\title{
Studies on the Role of Cephalic-Vagal
}

\section{Stimulation in the Acid Secretory Response to Eating in Normal Human Subjects}

\author{
Charles T. Richardson, John H. Walsh, Kathleen A. Cooper, \\ MarK Feldman, and John S. FordTran
}

From the Departments of Internal Medicine, Divisions of Gastroenterology, The University of Texas Southwestern Medical School and Veterans Administration Hospital, Dallas, Texas 75235 and the University of California at Los Angeles, Los Angeles, California 90093

AB S TRACT These experiments were performed to determine the importance of cephalic-vagal stimulation in the acid secretory response to eating in normal human subjects. Cephalic stimulation was induced by a modified sham feeding (MSF) technique, during which subjects chewed and expectorated appetizing food. The response to MSF was compared with that to gastric distention with $600 \mathrm{ml} \mathrm{NaCl}$, glucose, or food. In addition, we measured the extent to which cephalic stimulation augments acid secretion that has been stimulated simultaneously by these other mechanisms.

Our conclusions are as follows: (a) cephalic stimulation accounts for approximately one-third of the acid secreted when all mechanisms act simultaneously (food-distention plus MSF); (b) within the limits imposed by the maximal secretory capacity, the response to MSF is approximately the same, regardless of whether acid secretion is otherwise unstimulated or is stimulated simultaneously by gastric distention with $\mathrm{NaCl}$, glucose, or food; and (c) gastric distention prolongs the response to cephalic stimulation.

\section{INTRODUCTION}

Eating food is believed to stimulate gastric acid secretion by three major physiological mechanisms: (a) cephalic-vagal stimulation secondary to anticipating, seeing, smelling, tasting, chewing, and swallowing food; (b) gastric distention which stimulates cholinergic reflexes in the body and fundus of the stomach

\footnotetext{
Dr. Feldman is a Research Fellow in Gastroenterology supported by Training grant AM-07100 from the U. S. Public Health Service.

Received for publication 9 February 1977 and in revised form 18 April 1977.
}

$(1,2)$; and $(c)$ chemical reactions of food and digestive products with gastrointestinal mucosa, causing the release of stimulants of acid secretion such as gastrin $(3,4)$. It has also been suggested that amino acids and peptides may react directly with parietal cells to elicit acid secretion (5).

In humans, eating a steak meal stimulates acid secretion which, at its maximum, is approximately equal to the peak acid secretory response to a maximal dose of histamine (6). The relative importance of the three major physiologic mechanisms at various times during and after a meal has not been established, nor is it known to what extent cephalic stimulation augments acid secretion that has been stimulated by gastric distention or by food in the stomach.

There were two major purposes for the present experiments: first, to determine the relative secretory potency of cephalic-vagal stimulation, gastric distention with $\mathrm{NaCl}$, and gastric distention with food; and second, to measure the extent cephalic-vagal stimulation augments acid secretion that has been stimulated simultaneously by gastric distention with $\mathrm{NaCl}$, glucose, or food or by an intravenous infusion of pentagastrin. The effect of cephalic-vagal stimulation was assessed by measuring acid secretion in response to modified sham feeding $(\mathrm{MSF})^{1}(7)$.

\section{METHODS}

Subjects. Nine normal human subjects were studied with each stimulus (except that only five were studied with pentagastrin). Their mean age was $30 \pm 2$ yr (SEM) (range, 23-45 yr). Six were men and three were women. Basal

${ }^{1}$ Abbreviations used in this paper: MSF, modified sham feeding; PEG, polyethylene glycol. 
and peak acid secretory responses to $0.04 \mathrm{mg} / \mathrm{kg}$ subcutaneous histamine acid phosphate were $3.2 \pm 1.6$ and $32.7 \pm 4.6 \mathrm{meq} / \mathrm{h}$ (mean \pm SEM), respectively. Each subject was studied on separate test days after a $10-\mathrm{h}$ fast, and the experiments were performed in random order (except for the pentagastrin studies, which were performed after the other experiments were completed). The study was approved by a Human Research Review Committee and informed consent was obtained from each subject.

Gastric aspiration studies. Gastric contents were aspirated through a 16-Fr Salem sump tube (Sherwood Medical Industries, Inc., St. Louis, Mo.). The tip of the tube was placed in the gastric antrum under fluoroscopic control, and suction was applied for 48 out of every $60 \mathrm{~s}$ by a Stedman suction pump (American Cystoscope Makers Inc., Stamford Conn.). Each sample of gastric juice was collected for 15 min, the volume was measured, and hydrogen ion concentration was determined by the method of Moore and Scarlata (8).

In vivo intragastric titration studies. Acid secretion in response to $\mathrm{NaCl}$, glucose, or homogenized food infused into the stomach was measured by in vivo intragastric titration (6). Samples of gastric contents were obtained every 2-3 min through an Andersen tube $(H$. W. Andersen Products, Inc., Oyster Bay, N. Y.). pH was measured and the sample was returned to the stomach. Sodium bicarbonate $(0.3 \mathrm{~N})$ was infused through a small polyvinyl tube at the rate required to maintain $\mathrm{pH}$ at 5.0. The number of millequivalents of bicarbonate required to prevent a fall of gastric pH below 5.0 is equal to the number of milliequivalents of acid secreted.

Modified sham feeding (MSF). During a 30-min period, the subjects chewed and expectorated an appetizing meal consisting of $227 \mathrm{~g}$ sirloin steak, $142 \mathrm{~g}$ french-fried potatoes, and $300 \mathrm{ml}$ water. All meals were cooked in a separate building so that the subjects could not see or smell food until time for sham feeding. Subjects were trained in preliminary studies not to swallow food. During all experiments gastric aspirates were carefully examined for swallowed food, and none was found. As a further check, polyethylene glycol (PEG) was added to the 300-ml water part of the sham meal. Gastric samples were analyzed for PEG (9), and none was found.

Test meals. Three liquid test meals were given alone and in combination with MSF. Their composition was as follows: $\mathrm{NaCl}, 2.64 \mathrm{~g} \mathrm{NaCl}$; glucose, $14.6 \mathrm{~g}$ glucose; and homogenized food, $142 \mathrm{~g}$ ground lean cooked sirloin steak, $28 \mathrm{~g}$ bread, and $5 \mathrm{~g}$ butter. The meals were diluted with water to a final volume of $600 \mathrm{ml}$, and $\mathrm{pH}$ was adjusted to 5.0 by addition of sodium bicarbonate or hydrochloric acid. The osmolality of each meal was $138 \mathrm{mosmol} / \mathrm{kg}$. Meals were infused over a 5 -min period into the stomach through the Andersen tube.

Pentagastrin studies. On separate test days, either pentagastrin (Peptavlon, Ayerst Laboratories, New York), $6.0 \mu \mathrm{gm} /$ kg per h or $0.15 \mathrm{M} \mathrm{NaCl}$ was infused intravenously at a constant rate (Harvard infusion pump, Harvard Apparatus Co., Inc., Millis, Mass.) for $150 \mathrm{~min}$ in five normal subjects. Gastric acid secretion was measured by aspiration. A steady state of acid secretion was achieved by the end of the first 30 -min period. The effect of pentagastrin was assessed from 30 to $90 \mathrm{~min}$. From 90 to $120 \mathrm{~min}$ MSF was superimposed on the continuing intravenous $\mathrm{NaCl}$ or pentagastrin infusion. Measurement of acid secretion was continued for two 30-min periods after the onset of MSF. The order of the experiments was randomized.

Serum gastrin. Venous blood was collected through an indwelling catheter (small vein infusion set, Pharmaseal Laboratories, Glendale, Calif.) which was kept open by a slow saline infusion. Blood samples were obtained at $30-\mathrm{min}$ intervals during the 90 -min control period and at $15,30,45$, 60,90 , and $120 \mathrm{~min}$ after infusion of the meals and (or) MSF. The blood was allowed to clot and serum was obtained by centrifugation and stored at $-20^{\circ} \mathrm{C}$ until assayed.

Serum gastrin concentrations were measured by radioimmunoassay (10). All samples were tested in duplicate in the same assay. Antibody 1296, rabbit antigastrin prepared by immunization with gastrin conjugated to bovine serum albumin, was used at a final dilution of 1:300,000. With this antiserum, human heptadecapeptide gastrins (HG-17-I and HG-17-II) and human big gastrins (HG-34-I and HG-34-II) are measured on a nearly equimolar basis, big gastrins being approximately two-thirds as potent as heptadecapeptides. Cross reactivity with porcine cholecystokinin is less than $5 \%$ (11). Results are expressed in picograms per milliliter with natural human G-17-I used as standard.

Statistical analysis. Statistical significance of differences between mean values was determined with Student's $t$ test for paired values. All differences with $P<0.05$ are indicated in Figures and Tables.

\section{RESULTS}

Effect of MSF. Acid secretion rate in the basal state $(90 \mathrm{~min})$ and during and after $30 \mathrm{~min}$ of $\mathrm{MSF}$ is shown in Fig. 1 (left). As a control for MSF, the subjects chewed a piece of plastic tubing for $30 \mathrm{~min}$. Gastric contents were collected by aspiration, and each 15-min sample was analyzed.

Acid secretion was stable during the 90 -min basal period and did not change significantly during and after chewing plastic tubing. On the other hand, acid secretion increased from a basal level of $0.8 \mathrm{meq} / 15$ min to $5.6 \mathrm{meq} / 15 \mathrm{~min}$ during the second $15-\mathrm{min}$ period of MSF $(P<0.05)$. (For comparison, the peak acid output after histamine in these subjects was 8.2 $\mathrm{meq} / 15 \mathrm{~min})$. During the next $45 \mathrm{~min}$, acid secretion decreased so that by $75 \mathrm{~min}$ ( $45 \mathrm{~min}$ after MSF ended) acid secretion had returned to near basal levels.

The reproducibility of MSF is shown in Fig. 2 in five subjects who had two studies approximately $6 \mathrm{mo}$ apart. The correlation between the MSF response (acid secretion above the basal level) during the first and second studies was excellent with a correlation coefficient of $0.94(P<0.01)$.

As shown in Fig. 1 (right), serum gastrin concentration was not changed by aspiration of acid during the basal period nor by chewing plastic tubing. There was a slight increase in mean serum gastrin concentration during and after MSF, but the increase at each time period was not statistically significant $(P>0.10)$ when compared with basal levels or with levels after chewing plastic tubing.

Effect of gastric distention with $\mathrm{NaCl}$ or food. Basal acid secretion was measured by aspiration, and acid secretion after distention with $\mathrm{NaCl}$ or food was measured by in vivo intragastric titration. The results are shown in Fig. 3 (left). Acid secretion increased 
ACID SECRETION

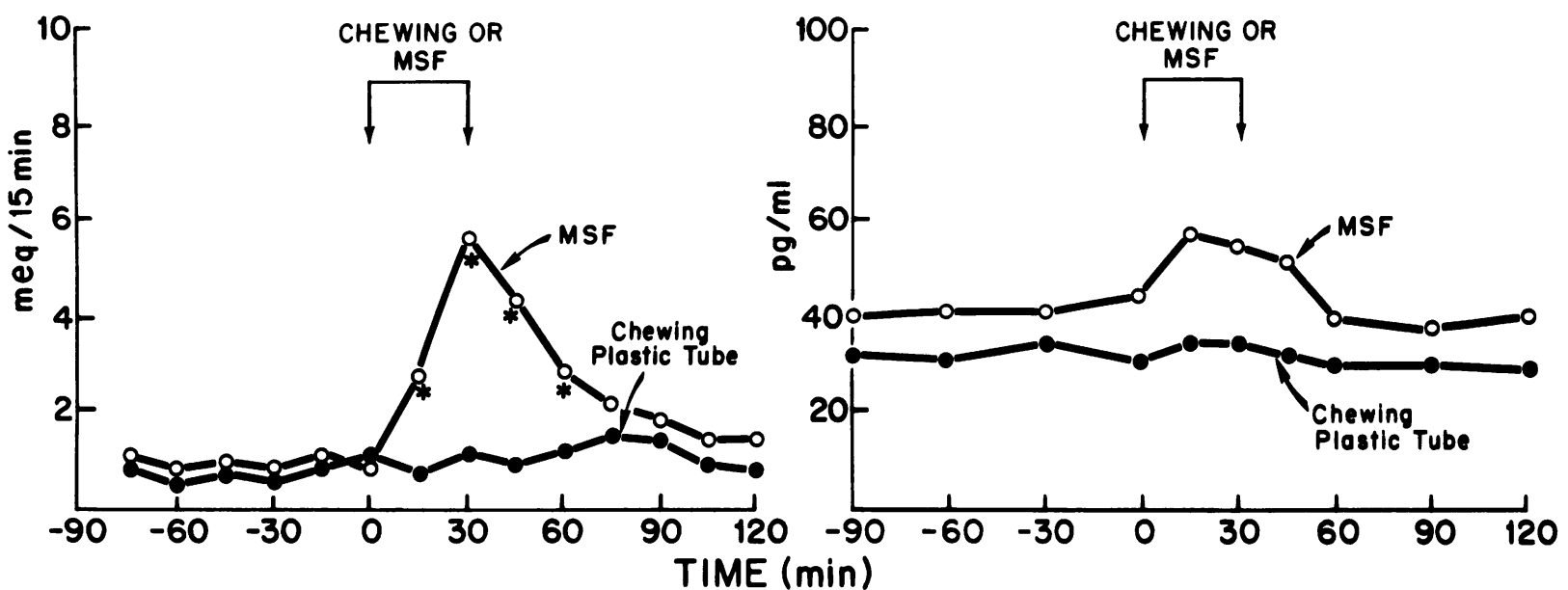

\section{SERUM GASTRIN CONCENTRATION}

Figure 1 Acid secretion and serum gastrin concentration in nine normal subjects in the basal state and during and after $30 \mathrm{~min}$ of chewing a plastic tube or MSF. Acid secretion was measured by aspiration. Statistically significant differences $(P<0.05)$ by paired $t$ test between the responses to MSF and chewing a plastic tube are shown by $\left({ }^{*}\right)$. from a basal level of 0.8 to $2.8 \mathrm{meq} / 15 \mathrm{~min}$ during the first 15-min period after gastric distention with $\mathrm{NaCl}(P<0.05)$; secretion remained near this level for the remainder of the experiment.

In contrast to distention with $\mathrm{NaCl}$, distention with food did not cause an increase in acid secretion during the first 15-min period. However, during subsequent periods, acid secretion was higher with food than with $\mathrm{NaCl}$ and reached a peak of $6.8 \mathrm{meq} / 15 \mathrm{~min}$ at $60 \mathrm{~min}$ $(P<0.05)$. (For comparison the peak acid output to histamine was $8.2 \mathrm{meq} / 15 \mathrm{~min})$.

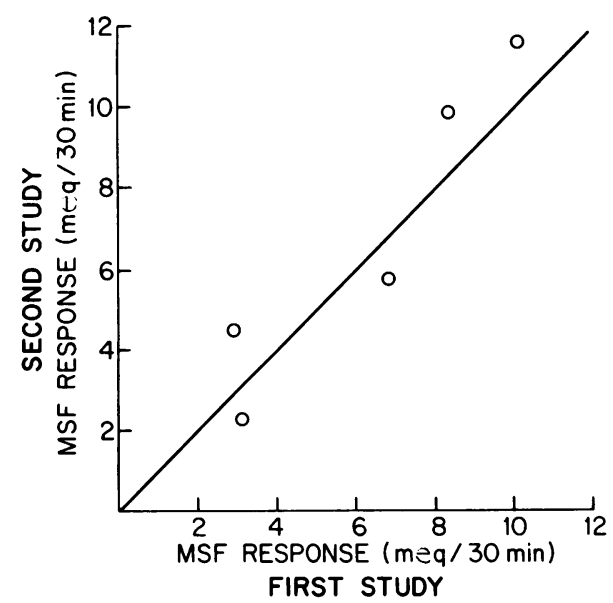

FIGURE 2 Reproducibility of MSF in five normal subjects. The MSF response (acid secretion above basal level) is shown for the $0-30$-min time period on 2 separate test days (approximately 6 mo apart). The line represents perfect identity and not the regression line of the experimental observations. Correlation coefficient $(r)$ for these observations is $0.94(P<0.01)$.
Distention with $\mathrm{NaCl}$ did not cause an increase in serum gastrin concentration over basal levels (Fig. 3 , right). Distention with food, on the other hand, caused a rise in serum gastrin concentration from approximately 30 to $96 \mathrm{pg} / \mathrm{ml}$. Serum gastrin concentration at each time period was significantly higher than basal values and also higher than those after $\mathrm{NaCl}$ (Fig. 3, right).

Relative potency of MSF and gastric distention with $\mathrm{NaCl}$, glucose, or food. Acid secretory response (acid secretion above basal or control level) to each stimulus is shown in Table I. During the first 30-min period, the MSF response was the most potent. The response to gastric distention with $\mathrm{NaCl}$ was present during the first 30-min period and remained near the same level during subsequent periods. During the first period, the response to glucose distention was approximately the same as with $\mathrm{NaCl}$, remained relatively steady during the second period, and then decreased during the last two periods. The food-distention response, on the other hand, was less than that with $\mathrm{NaCl}$ or glucose during the first period but during the latter periods was higher than any of the other responses. Peak acid secretory responses expressed as a percentage of the peak acid response to histamine (14.7 meq/30 min, basal acid secretion subtracted), were as follows: $\mathrm{MSF}, 45 \%$; $\mathrm{NaCl}$ distention, $24 \%$; glucose distention, $30 \%$; and food distention, $65 \%$.

Effect of MSF superimposed on $\mathrm{NaCl}$, glucose, and food-distention stimuli. Each subject was studied with and without MSF under four conditions: gastric aspiration (stomach empty) (Fig. 1) and gastric distention with $\mathrm{NaCl}$, glucose, or food (Fig. 4 and Table II). MSF had approximately the same effect on acid 


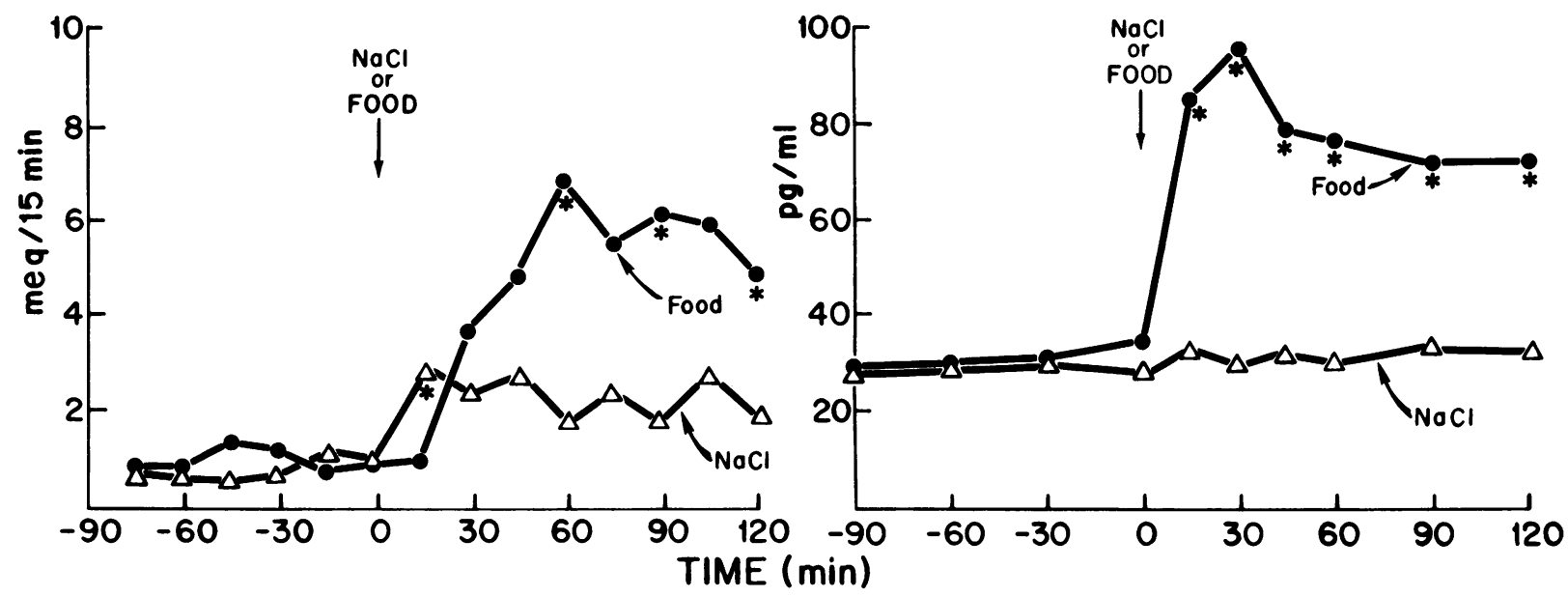

FIGURE 3 Acid secretion and serum gastrin concentration in nine normal subjects in the basal state and after $600 \mathrm{ml} \mathrm{NaCl}$ or homogenized food was infused into the stomach. Acid secretion was measured by in vivo intragastric titration. Statistically significant differences $(P<0.05)$ by paired $t$ test between food and $\mathrm{NaCl}$ responses are shown by $\left(^{*}\right)$.

TABLE I

Relative Potency of MSF and Gastric Distention with $\mathrm{NaCl}$, Glucose, or Food*

\begin{tabular}{lcccc}
\hline & \multicolumn{4}{c}{ Acid secretory response } \\
\cline { 2 - 5 } & $0-30 \mathrm{~min}$ & $30-60 \mathrm{~min}$ & $60-90 \mathrm{~min}$ & $90-120 \mathrm{~min}$ \\
\hline & \multicolumn{4}{c}{ meq/30 mint } \\
MSF & $6.6 \pm 1.4$ & $5.4 \pm 1.1$ & $2.2 \pm 0.9$ & $1.1 \pm 0.9$ \\
Gastric & & & & \\
$\quad$ distention & $3.5 \pm 0.7$ & $2.8 \pm 1.2$ & $2.6 \pm 0.6$ & $3.0 \pm 0.9$ \\
NaCl & $3.6 \pm 1.1$ & $4.4 \pm 1.1$ & $2.0 \pm 1.0$ & $1.0 \pm 0.6$ \\
Glucose & $2.6 \pm 1.7$ & $9.5 \pm 2.0$ & $9.6 \pm 2.6$ & $8.7 \pm 1.6$ \\
Food & & & &
\end{tabular}

* Response to MSF or gastric distention with $\mathrm{NaCl}$, glucose, or food is defined as acid secretion with each stimulus minus basal secretion. Basal acid secretion was measured before each experiment. Mean basal acid secretion before MSF was $1.7 \pm 0.9 ; \mathrm{NaCl}$ distention, $1.6 \pm 0.8$; glucose distention, $1.7 \pm 0.7$; and food distention $2.3 \pm 1.0 \mathrm{meq} / 30 \mathrm{~min}$.

\$ Mean \pm SEM.

secretion from $0-30$ and $30-60$ min whether the stomach was empty or distended by $\mathrm{NaCl}$, glucose, or food. On the other hand, the response to MSF was of longer duration when the stomach was distended than when it was empty (compare Fig. 1, left, with Fig. 4 , top panel). Peak acid secretion after MSF plus gastric distention with food was $9.7 \mathrm{meq} / 15 \mathrm{~min}$ (Fig. 4). This exceeded the peak acid output to histamine $(8.2 \mathrm{meq} / 15 \mathrm{~min})$ although the difference was not statistically significant.

The contribution of MSF (net effect of MSF) to acid secretion when all mechanisms were acting simultaneously (food-distention plus MSF) is shown in Table III. MSF accounted for $30-51 \%$ of the acid secreted in response to these combined stimuli. When the total 2-h period is considered, MSF contributed $36 \% .^{2}$

Under each experimental condition, the mean serum gastrin concentration was higher with MSF at all blood sampling intervals (Fig. 1, right and Fig. 4, bottom panel), and, at several intervals the differences were statistically significant.

Effect of MSF on pentagastrin stimulated acid secretion. The effect of MSF on acid secretion stimulated by a maximal dose of pentagastrin $(12,13)$ is shown in Table IV. MSF did not augment maximally stimulated acid secretion.

\section{DISCUSSION}

Cephalic-vagal stimulation of gastric acid secretion is thought to be mediated by direct cholinergic innervation of parietal cells and by cholinergic stimulation of gastrin release from the antrum and (or) duodenum (3). In dogs sham feeding causes a $100-130 \mathrm{pg} / \mathrm{ml}$ increase in serum gastrin concentration, provided acid

\footnotetext{
2 The net contribution of MSF to the total (all mechanisms acting simultaneously) 2 -h response $(60.7 \mathrm{meq})$ is also $36 \%$ when the MSF response superimposed on saline distention (21.9 meq) is used rather than the MSF response superimposed on food distention (as in Table III). Thus, the contribution of MSF to the overall response is the same, whether or not the MSF component is assessed with food in the stomach.
} 

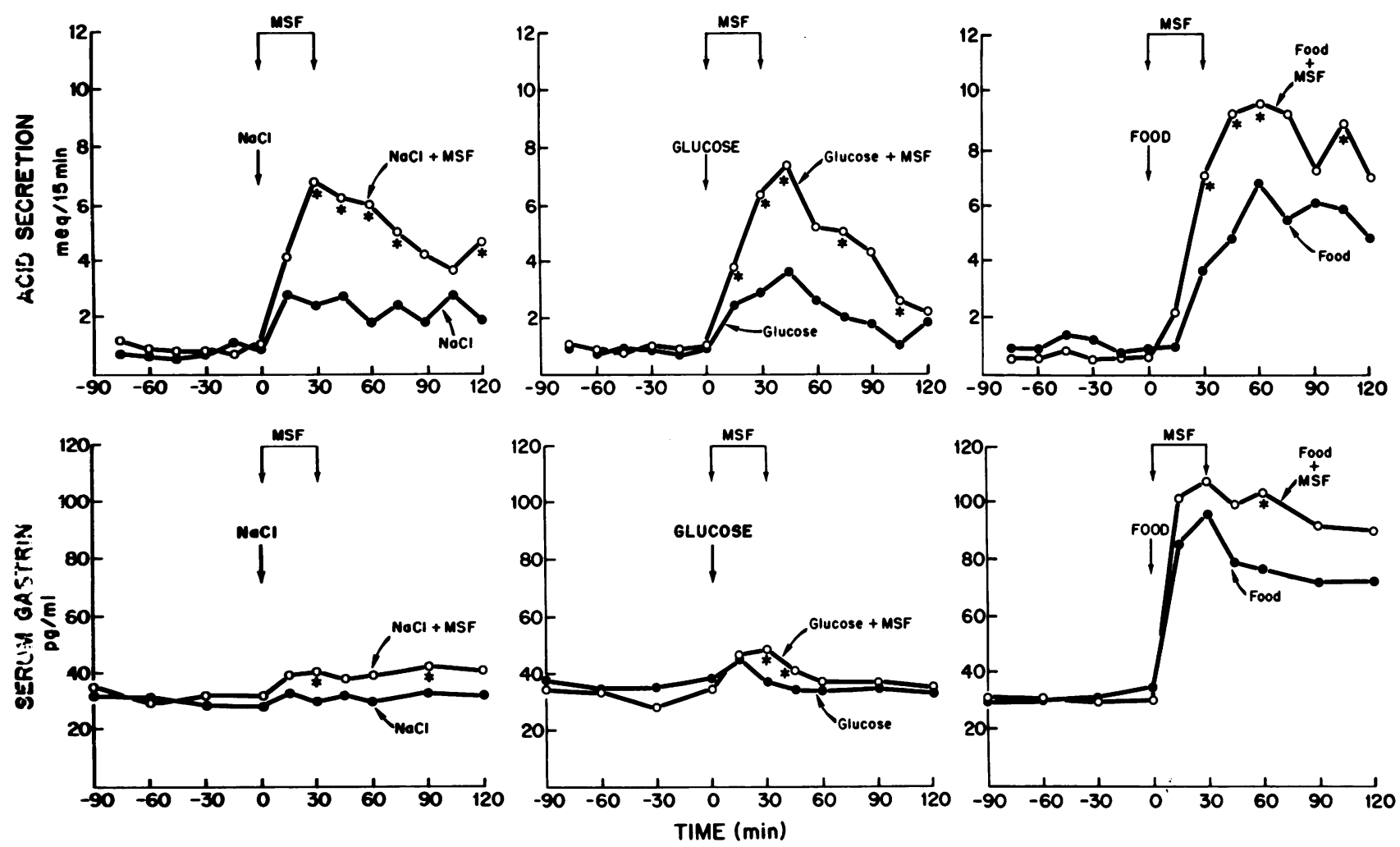

FIGURE 4 Acid secretion (top panel) and serum gastrin concentration (bottom panel) in nine normal subjects in the basal state and after $600 \mathrm{ml} \mathrm{NaCl}$, glucose, or homogenized food was infused into the stomach. Each experiment was performed with and without MSF. Statistically significant differences $(P<0.05)$ by paired $t$ test between each stimulus alone and with MSF is shown by $(*)$.

TABLE II

Acid Secretory Responses to MSF under Four Experimental Conditions

\begin{tabular}{lcccc}
\hline \multirow{2}{*}{$\begin{array}{c}\text { Background } \\
\text { stimulus }\end{array}$} & \multicolumn{4}{c}{ Acid secretory response to MSF } \\
\cline { 2 - 5 } & $0-30 \mathrm{~min}$ & $30-60 \mathrm{~min}$ & $60-90 \mathrm{~min}$ & $90-120 \mathrm{~min}$ \\
\hline $\begin{array}{c}\text { meq/30 } \mathrm{min}^{*} \\
\text { None } \\
end{array}$ & $6.6 \pm 1.4$ & $5.4 \pm 1.1$ & $2.2 \pm 0.9$ & $1.1 \pm 0.9$ \\
$\begin{array}{c}\text { NaCl } \\
\text { distention } \S\end{array}$ & $5.8 \pm 1.4$ & $7.6 \pm 2.2$ & $5.0 \pm 2.3$ & $3.5 \pm 1.4$ \\
$\begin{array}{c}\text { Glucose } \\
\text { distention } \$\end{array}$ & $4.6 \pm 1.2$ & $6.2 \pm 2.4$ & $5.4 \pm 2.1$ & $2.0 \pm 0.6$ \\
$\begin{array}{c}\text { Food } \\
\text { distention } \S\end{array}$ & $4.7 \pm 1.0$ & $7.2 \pm 2.3$ & $4.8 \pm 2.3$ & $5.0 \pm 3.0$ \\
\hline
\end{tabular}

* Mean \pm SEM.

\$ Acid secretion with MSF alone (gastric aspiration, stomach empty) minus basal acid secretion. Basal acid secretion was $1.7 \pm 0.9 \mathrm{meq} / 30 \mathrm{~min}$.

$\$$ Mean acid secretory response to MSF was calculated by subtracting the observed rate of acid secretion with the background stimulus alone from the observed rate of acid secretion with the background stimulus plus MSF in each subject. secreted in the fundus is diverted from the antrum (thus preventing feedback inhibition of gastrin release) $(14,15)$. The rise is less marked when normal gastric continuity allows acid to reach the antrum. Previous studies in normal humans have not shown a statistically significant increase in serum gastrin concentration with MSF $(7,16)$. However, in these studies acid secretion was measured by standard aspiration techniques which probably allow some acid to bathe the antral and duodenal mucosa. When we measured acid secretion by aspiration (Fig. 1), we also found that sham feeding did not cause a statistically significant increase in serum gastrin concentration. However, when the stomach was distended and intragastric $\mathrm{pH}$ maintained at 5.0 (Fig. 4), there was a $10-20 \mathrm{pg} / \mathrm{ml}$ rise in serum gastrin concentration with MSF, and this rise was statistically significant at several sampling intervals. We conclude that MSF increases serum gastrin concentration when the stomach is distended and gastric $\mathrm{pH}$ is 5.0 , although the rise is small compared to the gastrin response to sham feeding in dogs. The extent to which a $10-20 \mathrm{pg} / \mathrm{ml}$ rise in serum gastrin concentration contributes to the acid secretory response to MSF is 
TABLE III

Contribution of MSF to Acid Secretion* When All Mechanisms Are Acting Simultaneously

\begin{tabular}{|c|c|c|c|c|}
\hline & & & $0-30 \mathrm{~min}$ & \\
\hline \multicolumn{3}{|c|}{$\begin{array}{l}\text { Food distention } \\
\text { Food distention plus MSF } \\
\text { Net effect of MSF: } \\
\text { meq } 30 \min \S \\
\text { Percent of food distention } \\
\text { plus MSF, } \%\end{array}$} & $\begin{array}{c}4.6 \pm 1.7 \\
9.3 \pm 1.7 \\
4.7 \pm 1.0 \\
51\end{array}$ & \\
\hline \multicolumn{5}{|c|}{$\begin{array}{l}\text { * In contrast to data shown in Table } 1 \text { basal acid secretion ha } \\
\text { \$ Mean } \pm \text { SEM. } \\
\$ \text { Calculated by subtracting acid secretion with food distenti } \\
\text { subject. }\end{array}$} \\
\hline \multicolumn{5}{|c|}{$\begin{array}{c}\text { TABLE IV } \\
\text { Effect of MSF on Unstimulated and Maximally Stimulated } \\
\text { Acid Secretion in Five Normal Subjects }\end{array}$} \\
\hline \multirow{3}{*}{$\begin{array}{l}\text { Intravenous } \\
\text { infusate }\end{array}$} & \multicolumn{4}{|c|}{ Time, $\min$} \\
\hline & \multicolumn{2}{|c|}{ Before MSF } & \multicolumn{2}{|c|}{ During and after MSF } \\
\hline & $30-60$ & $60-90$ & $90-120$ & $120-150$ \\
\hline & \multicolumn{4}{|c|}{ meq/30 min* } \\
\hline $\begin{array}{l}0.15 \mathrm{M} \mathrm{NaCl} \\
\text { Penta- } \\
\quad \text { gastrin } ¥\end{array}$ & $1.3 \pm 0.8$ & $1.8 \pm 1.2$ & $\begin{array}{r}8.3 \pm 2.5 \\
26.6 \pm 4.1\end{array}$ & $\begin{array}{r}7.3 \pm 2.4 \\
25.2 \pm 4.2\end{array}$ \\
\hline
\end{tabular}

$*$ Mean \pm SEM.

$\$ 6.0 \mu \mathrm{gm} / \mathrm{kg}$ per $\mathrm{h}$.

not clear. Based on studies in which exogenous gastrin has been infused, and acid secretion compared with serum gastrin concentration (17), it seems likely that rises in gastrin concentration of this magnitude can cause some but not all of the acid secretory response to sham feeding in humans.

The contribution of the cephalic phase of acid secretion in the overall acid secretory response to eating has not been investigated previously. To evaluate the relative importance of cephalic-vagal stimulation, gastric distention and the chemical effects of food, we studied each of these stimulants in nine normal subjects. The peak secretory responses, expressed as a percentage of the peak histamine response, were 45,24 , and $65 \%$ for $\mathrm{MSF}$, gastric distention with $\mathrm{NaCl}$, and gastric distention with food, respectively. Thus, the peak MSF response was intermediate between the responses to $\mathrm{NaCl}$ and food distention and none of the responses, acting alone, caused maximum acid secretion. Although this is the first time that responses to these three stimulants have been measured and com-

pared in the same normal subjects, the response to each stimulant is similar to that found in previous studies $(7,16,18-20)$.

Not only were the peak secretory responses to the three stimulants different but also the patterns of acid secretion. The response to MSF was prompt but transient; soon after MSF was discontinued, acid secretion decreased rapidly and reached near basal rates within $45 \mathrm{~min}$. Gastric distention with $\mathrm{NaCl}$ initiated a prompt (but modest) secretory response that persisted at approximately the same level throughout the 2-h experiment. In contrast, the response to food was delayed for $15 \mathrm{~min}$, but then increased rapidly, reaching a peak at $60 \mathrm{~min}$. The 15-min delay in acid secretion presumably occurred because food released inhibitors which counteracted the acid stimulatory effects of distention and the increased serum gastrin concentration noted at 15 min (Fig. 3).

Since, under physiologic conditions, cephalic stimulation occurs in concert with other stimuli, we also measured the response to MSF when the stomach was distended. MSF caused approximately the same peak increment in acid secretion when the stomach was distended with $600 \mathrm{ml} \mathrm{NaCl}$ as it did when the stomach was empty, but distention prolonged the secretory response to MSF. Even at the end of the 2-h experiment, acid secretion was still significantly higher than the control rate noted with $\mathrm{NaCl}$ distention alone. This suggests that when the stomach has been primed by distention, the cephalic phase of acid secretion persists for at least $90 \mathrm{~min}$ after eating has ceased.

The next aspect of these studies was designed to determine the extent to which MSF augments acid secretion stimulated simultaneously by gastric distention with food. The net increment in acid secretion in response to MSF was the same whether MSF was the only stimulus or whether it was superimposed on a food distention stimulus. Thus, the effect of MSF is 
numerically additive with the effect of food distention. It might be argued that numerically additive responses suggest potentiation between stimuli. For example, for responses that obey Michaelis-Menton kinetics, the expected response to two nonpotentiating stimuli given simultaneously is less than (rather than numerically equal to) the sum of the responses to the two stimuli given separately. Unfortunately, it is not known if the parietal cell response to combined nonpotentiating stimuli would obey the Michaelis-Menton formula; therefore, our data does not prove or disprove potentiation between food-distention and cephalic-vagal stimulation of acid secretion.

In conclusion, within the limits imposed by the maximal secretory capacity, the peak response to MSF is approximately the same, regardless of the background rate of acid secretion or the background stimulus $(\mathrm{NaCl}$, glucose, or food). When the stomach is distended, as would occur when a meal is ingested, the secretory response to MSF is prolonged and continues for at least 90 min after sham feeding has been discontinued. Since cephalic-vagal stimulation accounts for approximately one-third of the acid secreted when all mechanisms act simultaneously (MSF plus food-distention), increased vagal activity secondary to cephalic influences is an important mediator of acid secretion during and after a meal is eaten.

\section{ACKNOWLEDGMENTS}

We wish to thank Helen Wong, Martha Hicks, and Jeanna Mathews for their expert technical assistance and Gayle Weinrobe for typing this manuscript.

This study was supported by Research grants AM-16816, AM-17294, and AM-17328 from the National Institute of Arthritis, Metabolism, and Digestive Diseases.

\section{REFERENCES}

1. Grossman, M. I. 1962. Secretion of acid and pepsin in response to distention of vagally innervated fundic gland area in dogs. Gastroenterology. 42: 718-721.

2. Grossman, M. I. 1961. Stimulation of secretion of acid by distention of denervated fundic pouches in dogs. Gastroenterology. 41: 385-390.

3. Grossman, M. I. 1967. Neural and hormonal stimulation of gastric secretion of acid. Handb. Physiol. 2 (Sect. 6. Alimentary Canal.): 835-863.

4. Debas, H. T., J. H. Walsh, and M. I. Grossman. 1975. Mechanisms of release of antral gastrin. In Symposium on
Gastrointestinal Hormones. J. C. Thompson, editor. University of Texas Press, Austin, Tex. 425-435.

5. Debas, H. T., and M. I. Grossman. 1975. Chemicals bathing the oxyntic gland area stimulate acid secretion in dog. Gastroenterology. 69: 654-659.

6. Fordtran, J. S., and J. H. Walsh. 1973. Gastric acid secretion rate and buffer content of the stomach after eating. Results in normal subjects and in patients with duodenal ulcer. J. Clin. Invest. 52: 645-657.

7. Mayer, G., R. Arnold, G. Feurle, K. Fuchs, H. Ketterer, N. S. Track, and W. Creutzfeldt. 1974. Influence of feeding and sham feeding upon serum gastrin and gastric acid secretion in control subjects and duodenal ulcer patients. Scand. J. Gastroenterol. 9: 703-710.

8. Moore, E. W., and R. W. Scarlata. 1965. The determination of gastric acidity by the glass electrode. Gastroenterology. 49: 178-188.

9. Hyden, S. 1955. A turbidometric method for the determination of higher polyethylene glycols in biological materials. Lantbrukshogsk. Ann. 22: 139-145.

10. Walsh, J. H., H. H. Trout, III, and H. T. Debas. 1974. Immunochemical and biological properties of gastrins obtained from different species and of different molecular species of gastrins. In Endocrinology of the Gut. W. Y. Chey and F. Brooks, editors. Charles B. Slack, Inc., Thorofare, N. J. 277-289.

11. Dockray, G. J., and J. H. Walsh. 1975. Amino terminal gastrin fragment in serum of Zollinger-Ellison Syndrome patients. Gastroenterology. 68: 222-230.

12. Pentagastrin as a stimulant of maximal gastric acid response in man. A multicentre pilot study. 1967. Lancet. I: $291-1295$.

13. Aubrey, D. A., and A. P. M. Forrest. 1970. Comparison of the gastric secretory responses following the administration of histamine acid phosphate and pentagastrin by separate continuous infusions or by a step-test method. Scand. J. Gastroenterol. 5: 449-457.

14. Nilsson, G., J. Simon, R. S. Yalow, and S. A. Berson. 1972. Plasma gastrin and gastric acid responses to sham feeding and feeding in dogs. Gastroenterology. 63: 51-59.

15. Maher, J. W., G. Wickbom, E. R. Woodward, J. E. McGuigan, and L. R. Dragstedt. 1975. The effect of vagal stimulation on gastrin release and acid secretion. Surgery (St. Louis). 77: 255-260.

16. Mignon, M., J. P. Galmiche, J. P. Accary, and S. Bonfils. 1974. Serum gastrin, gastric acid and pepsin responses to sham feeding in man. Gastroenterology. 66: 856. (Abstr.)

17. Feldman, M., C. T. Richardson, and J. S. Walsh. 1977. Mechanisms of the acid secretory response to amino acid solutions in normal man. Clin. Res. 25: 469A. (Abstr.)

18. Hunt, J. M., and I. MacDonald. 1952. The relation between the volume of a test meal and the gastric secretory response. J. Physiol. (Lond.). 117: 289-302.

19. Cooke, A. R. 1970. Potentiation of acid output in man by a distention stimulus. Gastroenterology. 58: 633-637.

20. Walsh, J. H., C. T. Richardson, and J. S. Fordtran. 1975. $\mathrm{pH}$ dependence of acid secretion and gastrin release in normal and ulcer subjects. J. Clin. Invest. 55: 462-468. 